\title{
Improving images of aging
}

The present issue of International Psychogeriatrics is the second one conveying data and reflections related to positive psychiatry (see Editorial: Jeste, 2018).

Three original papers, coming from Canada (Gough et al., 2018), Spain (Dumitrache et al., 2018), and the United States (Laird et al., 2018) contribute to this topic, each of them clarified by a commentary (Rapoport, 2019; Reynolds, 2019; Stoner, 2019).

The Canadian paper attracts the reader's attention with results from a knowledge transfer intervention which improved knowledge of evidencebased mental health, its application in everyday living, and knowledge about epigenetic factors in longevity (Gough et al., 2018). In her commentary, Stoner (2019) points out the importance of knowledge transfer interventions and their impact in psychoeducating research participants. Her emphasis on rigorous methodological approaches in such studies remains an essential task of future investigations.

The article from Spain (Dumitrache et al., 2018) gives results from a cross-sectional survey with persons who were 65 years of age and older showing that social relations and personality, specifically optimism, were associated with life satisfaction. Commenting this study, Rapoport (2019) highlights its message that satisfaction with later life is related to psychological and social resources; however, the psychosocial variables tested in this study only accounted for under half of the variance of overall life satisfaction. Rapoport, hence, raises the question to what degree the findings of Dumitrache and co-authors would be true in other countries, as satisfaction with one's own life depends on cultural constructs.

He rightly flags down the reader to the important aspect that in our day-to-day practices as geriatric psychiatrists we encounter patients struggling with severe mental illness, for whom the constructs comprising successful or satisfying aging are largely elusive (Rapoport, 2019).

The US paper (Laird et al., 2018) investigates different aspects of resilience in adults of 60 years of age and older suffering from major depressive disorder. Their factor analysis yields four constructs: grit, active coping self-efficacy, accommodative coping self-efficacy, and spirituality. Furthermore, the authors' best-fit model found less depression, less apathy, greater clinicianrated medical comorbidity, higher quality of life, and minority race to best explain the variability in resilience measures. The accompanying commentary by Reynolds (2019) points out the fact that, due to the cross-sectional and observational nature of the study, reported correlations cannot be interpreted as implying causality, as authors also note. Methodological approaches with prospective assessments should be designed in the future. As Reynolds stresses, in addition, future studies in this field should encompass appropriate biomarkers of risk as well as therapeutic interventions cultivating core factors in resilience in order to discover the relationship and interplay of behavioral with biological variables (Reynolds, 2019).

Which topics of positive psychiatry are mainly addressed by these papers and their commentaries?

First, the importance of psychosocial interventions and psychoeducation with a transfer of knowledge to correct for exclusively negative associations and myths concerning age and aging, to promote appropriate reflections about elderly people still possessing positive and productive strengths and resources for managing their day to day life tasks, to learn to know the "dynamic interplay between positive and negative psychological processes and outcomes" (Stoner, 2019), especially while suffering from acute or enduring chronic diseases, and, finally, to improve prevention and health rescuing behavior.

Second, the multi-faceted dimensions related to overall satisfaction with life in the elderly, including somatic, psychological, social, and economic variables, all of which may contribute to explaining conceptions of successful or satisfying aging.

Third, Rapoport (2019) reminds us of the need for conceptual approaches of positive psychiatry for the most seriously mentally ill patients. If there is not any option left to count on a sufferer's activity, creativity, communication abilities, optimism, or coping strategies, what then could still be the impact of positive psychiatry? Whatever these considerations may eventually lead to, it will, in any case, remain our assignment as medical doctors to encounter the severely ill as subjects owning dignity, 
communicating on eye level with them beyond being simply a case to be cared for. Practicing this kind of positive action, we give back dignity to the most seriously ill which they threaten to lose otherwise. This attitude is constitutive for geriatric psychiatrists. Related to the notion of "positive" psychiatry, a hidden trap may lie in wait. Seriously mentally ill patients with - medically spoken almost negative attributions because of immobility, multimorbidity, severe dementia, or the need for comprehensive care in basic activities in daily living may be tipped out of social partnership (BMFSFJ, 2010).

There is another interesting aspect to consider, while reading the three papers and commentaries from this issue. The papers come from Canada, Spain, and the United States. The December issue of International Psychogeriatrics contained three papers referring to positive psychiatry that were from France, the United States, and from Switzerland (Jeste, 2018). In his editorial, Jeste (2018), moreover, gave emphasis to a study of rural southern Italy reporting of positive psychological traits in nonagenarians and centenarians (Scelzo et al., 2018). This international psychiatric work widens the field of positive psychiatry to a neighbor discipline that deserves attention at this point: cultural gerontology.

Let us take a short look on what are the objects of interest in cultural gerontology! Cultural gerontology draws together work across the humanities and social sciences (Twigg and Martin, 2014). It emerged out of a desire to escape the dominant paradigm that emphasized frailty and burden in the elderly. It challenges outdated, inadequate stereotypes and brings new theories and methodologies. Cultural gerontology prefers to adopt a life-course perspective aiming to reconnect older people with the younger mainstream, accentuating continuity rather than division (Twigg and Martin, 2014). It suggests that in late modern society the experience of age has itself changed, becoming more diverse, and aims to produce a fuller and richer account of later years. Cultural gerontology, therefore, introduces new, versatile, and dynamic images of aging into the debate on age and aging in order to correct old stereotypes of age as dull, depressing, or even unworthy (Wellin, 2018). It opens the potentials the elderly own and, hence, by improving the images of aging, contributes to a rectification of inadequate images that not only society but also the elderly themselves keep up. In our era of obviating illness as well as highlighting early diagnoses of diseases and their treatment, these predominantly negative images of aging may be even deleterious to health and well-being, as the elderly may become less compliant with health recommendations from medicine relating to prevention or advisable medical consultations and may neglect proposals for and adherence to treatment interventions.

In Germany, the percentage of elderly people who consult their general practitioner because of depressive or cognitive symptoms is, roughly, with less than $50 \%$ still too low (Haupt and Schneider, 2017; Haupt et al., 2018). Too often, the elderly, their community, and even medical doctors perpetuate the assumption that depressive symptoms or memory impairment rather are natural consequences within the process of aging, careful diagnosis and treatment were not necessary and the older individuals should better cope with it on their own (BMFSFJ, 2010). Recent developments in the German health system concerning medical supply of the mentally ill are promising, though its components of availability and integrative cooperation still await improvement (van Treeck et al., 2017)

In addition, elderly people upholding a negative self-image perform less physical activities compared to those with a positive self-image, despite of having a comparable good or bad health status, respectively (Wurm et al., 2010). A considerable number of elderly people, predominantly those with a negative self-image, still seem to presume that their physical status should be merely conserved rather than actively stabilized.

Moreover, what are the inappropriate images of aging lying behind the fact that, on the one hand, there is an overwhelming supply with pharmacological treatment in the elderly suffering from psychiatric disorders, but, on the other hand, there are completely insufficient rates of psychotherapeutic interventions within this age group (Melchinger, 2011)? Here, again, we encounter old-fashioned and outdated images of aging as a process of absent plasticity and absent willingness to develop effective behavioral patterns and satisfying solutions within the third and fourth age (Kruse, 2005) or as an irreversible organic decline that may only be mitigated by biochemical substances.

Cultural gerontology, as a scientific discipline of the humanities, investigating images, reflections, and behavioral patterns of the elderly within our societies of long life, may be a helpful co-contributor to achieving the goals of positive psychiatry. Both disciplines may stimulate each other in empirical research projects and methodological techniques to unbundle the complex questions which focus on positive and effective conditions yielding well-being and satisfaction in later life. All three commentaries (Rapoport, 2019; Reynolds, 2019; Stoner, 2019) of 
the respective original papers in this issue remind us of the requirement of this future research to develop and establish appropriate conceptual models as well as to define robust methodological study designs. If this research yields reliable results, it will, hopefully, enhance our knowledge about which supporting strategies are appropriate for older and mentally ill individuals in their respective countries and with their respective cultural traditions and customs.

\section{Martin Haupt, MD}

Private Practice for Psychiatry and

Psychotherapy/Neuro-Centrum Düsseldorf, Teaching

Practice of the Klinik und Poliklinik für Psychiatrie und

Psychotherapie der Heinrich-Heine-Universität

Düsseldorf, Düsseldorf, Germany.

E-mail: m.haupt@alzheimer-praxis-duesseldorf.de

\section{Acknowledgment}

I would like to dedicate this editorial with gratitude to my teacher Hans Lauter in Munich.

\section{References}

BMFSFJ: Bundesministerium für Familie, Senioren, Frauen und Jugend (2010). Sechster Bericht zur Lage der älteren Generation in der Bundesrepublik Deutschland. Altersbilder in der Gesellschaft (Sixth Report on the Situation of the Older Generation in Germany). Deutscher Bundestag. Drucksache 17/3815. Berlin.

Dumitrache, C. G., Rubio, L. and Cordon-Pozo, E. (2018). Successful aging in Spanish older adults: the role of psychosocial resources. International Psychogeriatrics, 31, 181-191.

Gough, A., Cassidy, B., Rabheru, K., Conn, D., Canales, D. D., and Cassidy, K.-L. (2018). The Fountain of Health: effective health promotion knowledge transfer in individual primary care and group community-based formats. International Psychogeriatrics, 31, 173-180.

Haupt, M. and Schneider, F. (2017). Psychische Erkrankungen bei älteren Patienten (Mental Diseases in Older Patients). In: F. Schneider (Ed.), Facharztwissen Psychiatrie, Psychosomatik und Psychotherapie (pp. 583-595). Berlin: Springer.
Haupt, M., Wolter, D. and Gutzmann, H. (2018). Psychische Erkrankungen im höheren Lebensalter (Mental Diseases in Later Life). In: H.-J. Möller, G. Laux, and H.-P. Kapfhammer (Eds.), Psychiatrie, Psychotherapie, Psychosomatik. 4. Bd. (pp. 2846-2873). Berlin: Springer.

Jeste, D. V. (2018). Positive psychiatry comes of age. International Psychogeriatrics, 30, 1735-1738.

Kruse, A. (2005). Störungen im Alter: Intervention (disorders in old age: intervention). In: M. Perrez and U. Baumann (Eds.), Klinische Psychologie und Psychotherapie (pp. 1087-1103). Bern: Huber.

Laird, T. K. et al. (2018). Clinical correlates of resilience factors in geriatric depression. International Psychogeriatrics, 31, 193-202.

Melchinger, H. (2011). Psychotherapie vs. Fachärztliche Behandlung in der ambulanten psychiatrischen Versorgung (selective importance of psychotherapy and psychiatric treatment in outpatient mental healthcare). Monitor Versorgungsforschung, 2, 35-40.

Rapoport, M. (2019). Life satisfaction in older adults in Spain: beyond subjective health. International Psychogeriatrics, 31, 167-168.

Reynolds, C. F. (2019). Promoting resilience, reducing depression in older adults. International Psychogeriatrics, 31, 169-171.

Scelzo, A. et al. (2018). Mixed-methods quantitative-qualitative study of 29 nonagenarians and centenarians in rural southern Italy: focus on positive psychological traits. International Psychogeriatrics, 30, 31-38.

Stoner, C. R. (2019). Positive psychiatry/psychology for older adults: a new and important movement but robust methodology is essential. International Psychogeriatrics, 31, 163-165.

Treeck van, B., Bergmann, F. and Schneider, F. (2017). Psychosoziale Versorgung (psychosocial care systems). In: F. Schneider (Ed.), Facharztwissen Psychiatrie, Psychosomatik und Psychotherapie (pp. 11-31). Berlin: Springer.

Twigg, B. A. and Martin, W. (2014). The challenge of cultural gerontology. The Gerontologist, 55, 353-359.

Wellin, C. (2018). Critical Gerontology Comes of Age. London: Routledge.

Wurm, S., Tomasik, M. J. and Tesch-Römer, C. (2010). On the importance of a positive view on aging for physical exercise among middle-aged and other adults: cross-sectional and longitudinal findings. Psychology and Health, 25, 25-42. 